\title{
Evaluation of the efficacy of paclitaxel with curcumin combination in ovarian cancer cells
}

\author{
ZENG LIU $^{1 *}$, YUAN-YUAN ZHU²* ${ }^{2 *}$ ZHAO-YUAN LI ${ }^{1}$ and SI-QING NING ${ }^{1}$ \\ ${ }^{1}$ Department of Nuclear Medicine, Central Hospital of Xiangyang, Xiangyang, Hubei 441021; \\ ${ }^{2}$ No. 1 Hospital of Xiangyang, Xiangyang, Hubei 441000, P.R. China
}

Received July 19, 2016; Accepted September 20, 2016

DOI: $10.3892 / 01.2016 .5192$

\begin{abstract}
The aim of the present study was to evaluate the efficacy of paclitaxel combined with curcumin (CUR) against drug resistance in ovarian cancer cells. PLGAphospholipid-PEG nanoparticles were prepared using the nano precipitation method. The size and morphology of the nanoparticles were determined using a transmission electron microscope and particle size analyzer. The encapsulation efficiency of nanoparticles was determined using the ultrafiltration centrifugation method. The dialysis method was used to study the release of PLGA-phospholipid-PEG nanoparticles. ADM was used to induce the A2780 cell line (human ovarian cancer cell line) to establish the model of the multidrug-resistant (MDR) cell line, and the protein activity of P-glycoprotein (P-gp) in the A2780 cell line and A2780/ ADM resistant cell line was determined using western blot analysis. The results showed that, the prepared nanoparticles were uniform in size, with a size of approximately $100 \mathrm{~nm}$, and round in shape. Additionally, the nanoparticles had a more gentle and slow release than the free drug release. The results of the protein trace printing experiment showed that the P-gp content of the drug-resistant cell line was significantly reduced by the CUR nanoparticles. In conclusion, PLGA-phospholipid nanoparticles containing taxol and CUR have improved solubility and stability together with a slow release effect. In addition, CUR was able to overcome the MDR of tumor cells by elevating the paclitaxel concentration in the tumor cells to improve the antitumor activity of this combination.
\end{abstract}

Correspondence to: Dr Zhao-Yuan Li or Dr Si-Qing Ning, Department of Nuclear Medicine, Central Hospital of Xiangyang, 136 Jinzhou Road, Xiangyang, Hubei 441021, P.R. China

E-mail: dt7466843zongm@163.com

E-mail: zn8534652heqin302@163.com

${ }^{*}$ Contributed equally

Key words: paclitaxel, curcumin, ovarian cancer, nanoparticles, multidrug resistance

\section{Introduction}

Ovarian cancer is a common malignant tumor of the female genital organs, and has the highest mortality rate among all gynecological types of cancer (1). After many years of research, there is more in-depth understanding of the syndrome; nevertheless, no significant decrease in ovarian cancer mortality has been observed. Thus, the identification of new and more effective drug targets or therapeutic agents is imperative (2).

Paclitaxel is an important therapeutic drug primarily used against ovarian cancer, breast cancer, lung cancer, colorectal cancer, melanin tumor, head and neck cancer, lymphomas and brain tumors with certain curative effect (3). On the other hand, curcumin (CUR) is a phytochemical with hypolipidemic, antitumor, anti-inflammatory and antioxidation effects (4).

In the present study, the preparation was loaded with PLGA-phospholipid nanoparticles of paclitaxel and CUR. The combination resulted in an increase in solubility and stability. CUR was able to overcome the multidrug resistance (MDR) of tumor cells, enhanced the amount of paclitaxel in tumor cells and thus improved the antitumor activity.

\section{Materials and methods}

Preparation of PLGA-phospholipid-PEG nanoparticles. The phospholipids and DSPE-PEG-COOH soluble in the mass fraction of $4 \%$ of the ethanol solution were prepared with the concentration of $1 \mathrm{mg} / \mathrm{ml}$ solution. The solution of phospholipid $(1 \mathrm{mg} / \mathrm{ml})$ and DSPE-PEG-COOH solution $(1 \mathrm{mg} / \mathrm{ml})$ was dissolved in water in a heated $\left(65^{\circ} \mathrm{C}\right)$ water bath for $3 \mathrm{~min}$. The PLGA acetonitrile solution $(10 \mathrm{mg} / \mathrm{ml})$ and drug solution $(1 \mathrm{mg} / \mathrm{ml})$ were mixed in acetonitrile, under continuous magnetic stirring for $10 \mathrm{~min}$. Subsequently, the organic phase was then quickly injected into the aqueous phase. This resulted in the formation of polymer phospholipid hybrid nanoparticles. The nanoparticles were removed, and centrifuged at $800 \mathrm{x} \mathrm{g}$ for $10 \mathrm{~min}$. The upper nano suspension was retained for the experiment.

Establishment of the MDR cell line model. To prepare the culture cryopreserved A2780 cells were transferred from a $-80^{\circ} \mathrm{C}$ deep freezer to a $37^{\circ} \mathrm{C}$ water bath, for thawing and melting. Frozen storage tubes were opened after the addition 

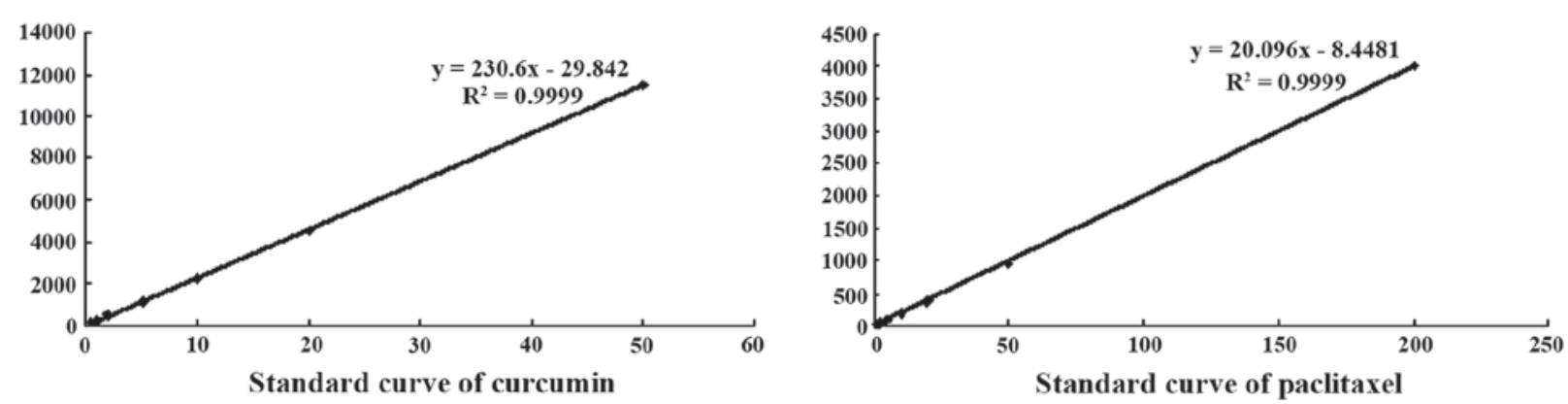

Figure 1. The standard curve of curcumin and paclitaxel.

of $75 \%$ alcohol for disinfection. The cell suspension was then transferred to the centrifuge tube, 5-fold the volume of culture medium was added, the cells were dispersed with gentle pipetting, and cell culturing continued in a $37^{\circ} \mathrm{C}$ incubator $\left(5 \% \mathrm{CO}_{2}\right.$, relative humidity of 90 ). When the cells adhered to the flask wall, the medium was aspirated off and phosphate-buffered saline (PBS) was used to wash the medium cell surface. It was followed by the addition of $2 \mathrm{ml}$ trypsin digestion liquid. After uniform suspension, the cells were passaged.

A2780/ADM-resistant cell lines with stable resistance to ADM were induced by stepwise increase of ADM concentrations. A2780 cells were cultured according to the method mentioned above, and ADM was added to the culture medium. The initial concentration was $20 \mathrm{nM}$, and the concentration of taxol in the culture medium was increased in the following order: 40, 100 and $200 \mathrm{nM}$. Each concentration was stable for three generations. Cell growth, morphology and drug resistance were regularly investigated, and the cells of stable passages, i.e., A2780/ADM cells, were considered resistant.

Main reagents. The main reagents used were: PLGA (SigmaAldrich, St. Louis, MO, USA); DSPE-PEG-COOH (Avanti Polar Lipids, Inc., Alabaster, AL, USA); phospholipid (MP Biomedicals, LLP, Santa Ana, CA, USA); anti-actin ( $\beta$-actin) and anti-P-glycoprotein (P-gp) antibody (CST, Beverly, MA, USA); and a BCA protein assay kit (Beyotime Institute of Biotechnology, Shanghai, China).

Structure elucidation of PLGA-phospholipid-PEG nanoparticles. The particle size and zeta potential ( $\zeta$-potential) were measured using a dynamic light scattering instrument (Wyatt Technology, Goleta, CA, USA, and the shape and surface morphology of the nanoparticles were observed using a transmission electron microscope (Philips, Eindhoven, The Netherlands).

Encapsulation efficiency of PLGA-phospholipid-PEG nanoparticles was determined by the ultrafiltration centrifugation method. The entrapment efficiency of the drug was calculated according to the formula: $\mathrm{E}(\%)=($ dosage - free drug content)/dosage x $100 \%$.

Release rate of PLGA-phospholipid-PEG nanoparticles. The free paclitaxel and nanoparticle suspension of paclitaxel with CUR was placed in the dialysis bag (10 kDa molecular weight interception). It was dispersed in a pH 7.4 PBS buffer followed by incubation at $37^{\circ} \mathrm{C}$. It was then sampled with fresh buffer at time intervals of $0,2,4,6,8,12,24,48$ and $72 \mathrm{~h}$. The HPLC method was used to study the release rates.

Western blot analysis for the determination of $P$-gp protein expression in cells. The free paclitaxel, and the combination of drugs were incubated in the cells for $24 \mathrm{~h}$. The cells were then digested and the total protein was extracted. The proteins were separated by polyacrylamide gel electrophoresis and transferred onto the cellulose membrane. The cellulose membrane, the rabbit polyclonal P-gp antibody (Abcam, Cambridge, MA, USA; catalog no. ab103477; dilution: $1: 500)$, and the mouse monoclonal $\beta$-actin antibody (Abcam; catalog no. ab8226; dilution: 1:500) were incubated at $4^{\circ} \mathrm{C}$. At $25^{\circ} \mathrm{C}$, the cells were incubated with two levels of antibody for $2 \mathrm{~h}$, and the protein activity was determined. This method was applied for the establishment of a MDR cell model and the MDR protein expression measurement in the cell incubation experiments of nanoparticles and free drugs.

Statistical analysis. SPSS20.0 software (SPSS Chicago, Ill) SPSS 19.0 software (IBM, Armonk, NY, USA) was used for statistical analysis. Quantitative data were presented as mean \pm standard deviation. Comparison between groups was carried out using one-way ANOVA test followed by the post hoc test (LSD). Percentage (\%) was used to express the enumeration data and the Chi-square test was used for data analysis. Comparisons between ranked data were performed using the non-parametric rank sum test. $\mathrm{P}<0.05$ indicated a statistically significant difference.

\section{Results}

Establishment of analytical method. The contents of CUR and docetaxel were measured using the HPLC method; the two standard curves are shown in Fig. 1. CUR and paclitaxel were within the linear range of $0-50$ and $0-200 \mu \mathrm{g} / \mathrm{ml}$. The concentration and peak area showed good correlation.

Measurement of the morphology, particle size and $\zeta$-potential of PLGA-phospholipid-PEG nanoparticles. The morphology of the nanoparticles was measured using a transmission electron microscope (Fig. 2). The results showed that the size of the nanoparticles formed by the self-assembly of PLGA and phospholipids in solution was uniform and the shape of the nanoparticles was uniform. 


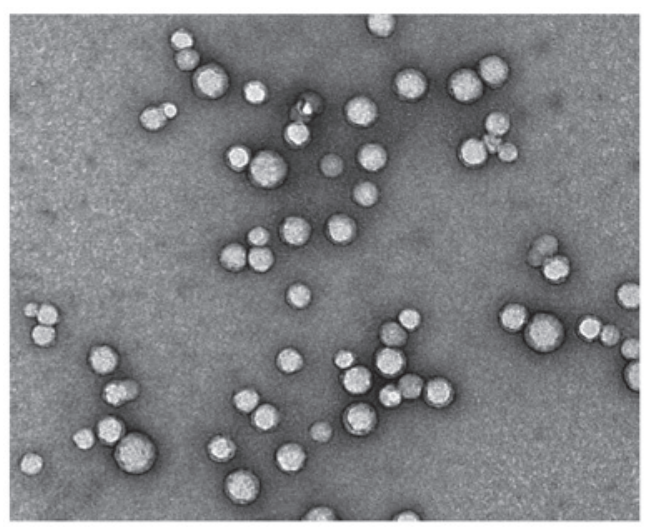

Figure 2. Morphology of nanoparticles.

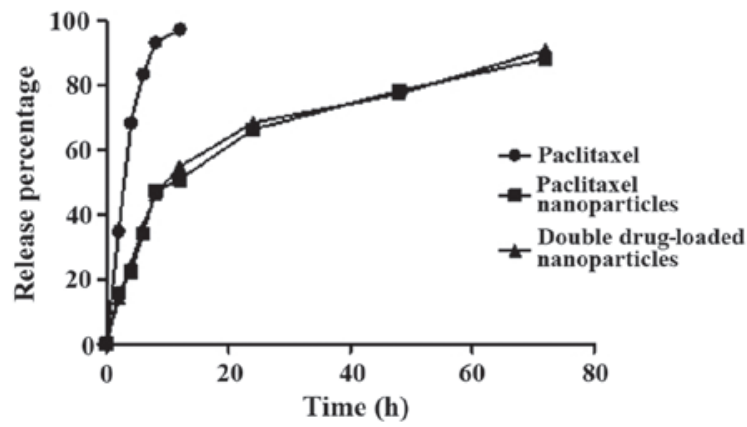

Figure 3. The release curve of nanoparticles.

The particle size and $\zeta$-potential of nanoparticles were determined by the dynamic light scattering method (Table I). The prepared CUR, paclitaxel and double drug-loaded nanoparticles were $<100 \mathrm{~nm}$, and PDI was $<0.2$, which showed that the size distribution of the nanoparticles was small, and suitable for the size of the nanoparticles. The ultrafiltration centrifugation method was used to measure the entrapment
Table I. The particle size, zeta ( $\zeta)$, encapsulation efficiency and PDI value of the nanoparticles.

\begin{tabular}{lcccc}
\hline & $\begin{array}{c}\text { Particle } \\
\text { size } \\
\text { Formulation }\end{array}$ & $\begin{array}{c}\zeta \text {-potential } \\
(\mathrm{mm})\end{array}$ & $\begin{array}{c}\text { Drug } \\
\text { encapsulation } \\
(\%)\end{array}$ & PDI \\
\hline $\begin{array}{lcccc}\text { CUR nanoparticles } \\
\text { Paclitaxel-loaded }\end{array}$ & 89.4 & -29.8 & 90.41 & 0.13 \\
$\begin{array}{l}\text { nanoparticles } \\
\begin{array}{l}\text { Double drug-loaded } \\
\text { nanoparticles }\end{array}\end{array}$ & 94.1 & -32.5 & 84.44 & 0.10 \\
\hline
\end{tabular}

CUR, curcumin

efficiency of the nanoparticles, which were all $>80 \%$, showing the two drugs can more be completely encapsulated in nano materials. Additionally, the $\zeta$-potential was approximately $-30 \mathrm{mV}$

Release of PLGA-phospholipid-PEG nanoparticles. The release curves of free paclitaxel, paclitaxel-loaded nanoparticles and double drug-loaded nanoparticles in the PBS buffer solution of $\mathrm{pH} 7.4$ were studied. The results are shown in Fig. 3. Free paclitaxel was released $\sim 70 \%$ in $4 \mathrm{~h}$, and almost completely in $8 \mathrm{~h}$. On the other hand, nanoparticles were released only $\sim 50 \%$ in $24 \mathrm{~h}$, while they were released up to $80 \%$ in $48 \mathrm{~h}$ and up to $90 \%$ in $72 \mathrm{~h}$, confirming the slow release effect. Furthermore, the release curves of two types of nanoparticles were without any significant difference.

Expression of P-gp protein was determined by western blot analysis. Western blotting was used to determine the expression intensity of P-gp in the A2780 and A2780/ADM cells (Fig. 4). For the two cell lines, the strips of free CUR and CUR
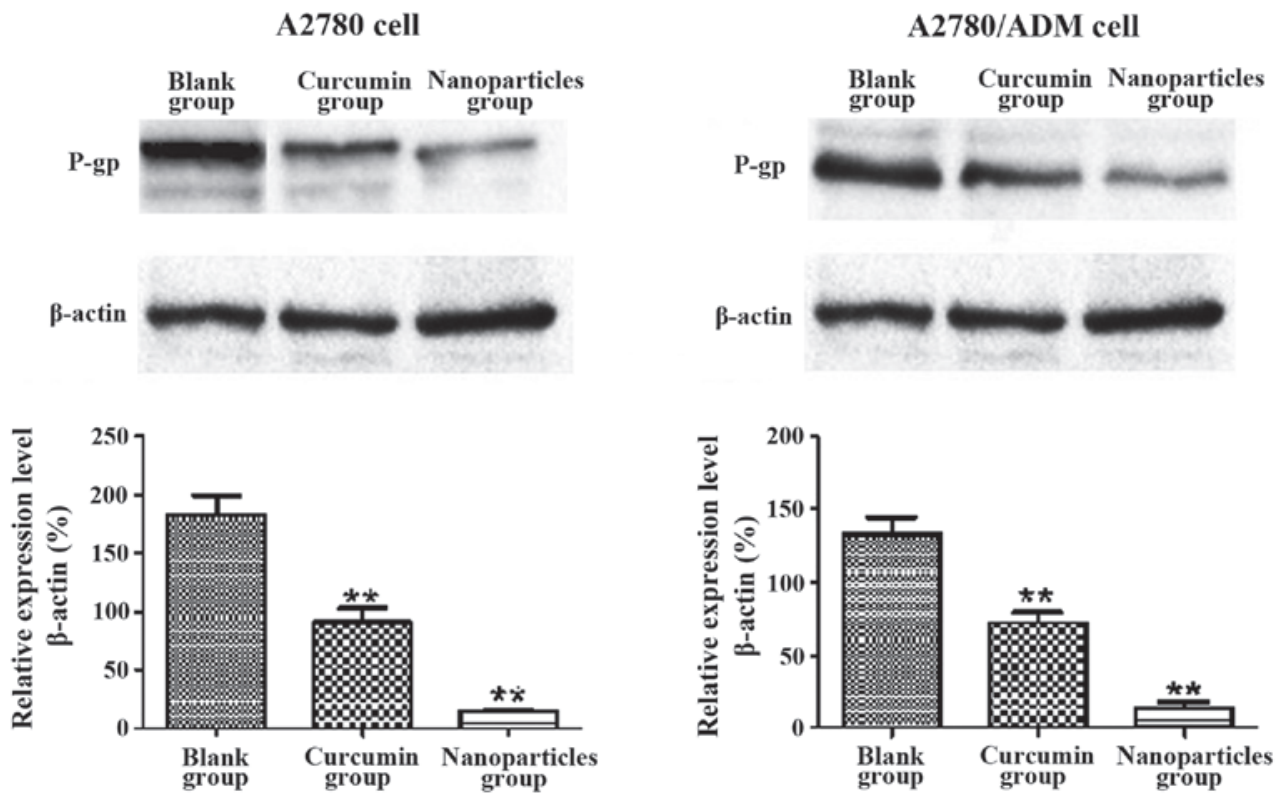

Figure 4. The expression of P-glycoprotein (P-gp) protein in the two types of cells. ${ }^{* *} \mathrm{P}<0.05$, compared to the control group. 
nanoparticles were lighter than the blank ones, showing CUR was able to reverse the MDR of the two cells. Compared with free drugs, the downregulation effect of nanoparticles on P-gp was more obvious. Furthermore, the CUR nanoparticles had a significant downregulation effect on P-gp cells of A2780/ADM cells in comparison with A2780 cells. The results clearly indicated the ability of CUR nanoparticles to reverse the MDR of tumor cells, in order that the cytotoxic drugs be more useful for the drug efficacy.

\section{Discussion}

New chemotherapy drugs continue to emerge, and chemotherapy regimens continue to improve. The widespread tumor MDR, has mainly remained the causative reason responsible for the failure of cancer therapy. It is a significant problem in chemical therapy and interventional treatment of tumor (5). For example, for ovarian cancer patients, more than $70 \%$ of patients initially are resistant to the treatment of drugs from Chinese fir, leading to relapse (6). The protein associated with drug efflux is the main cause of MDR in tumor cells. This efflux type of ATP-binding cassette transporter used ATP to produce energy for decomposition, remove the anticancer drug from inside the cell to outside to make antitumor drug concentration less than that required for killing of cells, leading to drug resistance (7). The ATP-binding cassette transporter family includes P-gp, MDR-associated protein (MRP), breast cancer resistance protein (BCRP), and the B-cell leukemia/ lymphoma gene 2 protein (Bcl-2) (8).

Reverse MDR was used to reduce the probability of failure of chemotherapy, with a high clinical value. MDR reversal has become one of the important directions in the research of chemotherapeutic drugs at home and abroad. Thus, a new type of nano drug loading system with the ability of coloading MDR modulators and chemotherapy drugs was selected (9).

The PLGA-phospholipid hybrid nanodrug loading system is a new type of core shell structure nanoparticle. The main advantages of the drug loading system in comparison to simple PLGA nanoparticles as well as liposome are: i) The core is composed of a biodegradable PLGA material, which is suitable for carrying poor water insoluble drugs, and can slowly release drugs at a constant speed; ii) the invisible material forms a hydrophilic outer shell (phospholipid-PEG), which prevents the nanoparticles from being swallowed by the immune system, and enhances the half-life of the nanoparticles in the body circulation; iii) phospholipid monolayer between the hydrophobic core and hydrophilic shell prevents drug leaking from the nanoparticles, while reducing the infiltration of moisture in the nanoparticles, thus, it has a high drug entrapment efficiency and drug release effect. iv) The surface of the nanoparticles can improve the active targeting of drugs by modifying the nucleic acid ligands or antibodies (10-12). Overcoming MDR through a drug delivery system is an important and effective reversal strategy in MDR. The drug carriers that have shown the ability to overcome the MDR of tumor cells included liposomes, micelles and nanoparticles. Drugs were wrapped in the carrier, could avoid the identification, binding and efflux of MDR-related proteins, in order that the drug was able to accumulate in the cell, without altering the in vivo disposal process of the drug. In addition, the drug carrier increased the drug concentration of the tumor tissue through the target function to overcome the MDR (13-15).

The PLGA phospholipid hybrid nanoparticles carrier delivery system has been used to successfully encapsulate anticancer drugs, including paclitaxel, and docetaxel, and examine the structure of the nanoparticles and in vitro cytotoxicity. Previous findings have shown that CUR has a variety of pharmacological effects such as antitumor, anti-inflammatory, antiviral, and antioxidant effects. Previous studies have indicated that CUR is effective in inhibiting the three major ATP-binding cassette transporters, including MDR1, MRP1, and ABCG2 (16). The anticancer activity of CUR occurs mainly due to its ability to block the transcription factor $\mathrm{NF}-\kappa \mathrm{B}$, a type of regulator of inflammation, cell proliferation, apoptosis and drug resistance, that can resist apoptosis and regenerate tumor cells. When CUR was combined with other active drugs, the pleiotropic effect of CUR was conducive to enhancing the biological utilization rate of drug activity in tumor tissue, and improving the level of intracellular drug activity. CUR water solubility was reduced albeit with a fast metabolism and low bioavailability. Previous findings have shown that nano preparation is able enhance the cytotoxicity of different tumor cell lines more than the prototype drug $(17,18)$. Paclitaxel is increasingly used in the clinical treatment of breast cancer, non-small cell lung cancer, pancreatic cancer, soft tissue sarcoma, head and neck cancer, gastric cancer, ovarian cancer and prostate cancer (19). Paclitaxel has an antitumor effect of broad spectrum, but almost has no inhibitory activity in MDR tumors with P-gp overexpression, primarily due to its being a good substrate for P-gp. Combination therapy was crucial in the treatment of cancer (20).

Since most of the pharmacological activity of anticancer drugs have MDR, MDR protein inhibitors with cytotoxic drugs are loaded in the novel carrier systems. Thus, these novel systems overcome MDR protein of tumor cells and at the same time, elevate drug concentrations in tumor cells. Therefore, we selected this model of the combination of CUR and paclitaxel. The dual drug-loaded PLGA phospholipid hybrid nano carrier delivery system overcame MDR and improved the efficacy of chemotherapeutic drugs. Additionally, the high specificity of nanoparticles was beneficial in minimizing the toxic and side effects of chemotherapeutic drugs in normal tissues.

\section{References}

1. Anton-Culver H, Cohen PF, Gildea ME and Ziogas A: Characteristics of BRCA1 mutations in a population-based case series of breast and ovarian cancer. Eur J Cancer 36: 1200-1208, 2000.

2. Bell DA: Origins and molecular pathology of ovarian cancer. Mod Pathol 18 (Suppl 2): S19-S32, 2005.

3. Stone GW, Ellis SG, Cox DA, Hermiller J, O'Shaughnessy C, Mann JT, Turco M, Caputo R, Bergin P, Greenberg J, et al; TAXUS-IV Investigators: A polymer-based, paclitaxel-eluting stent in patients with coronary artery disease. N Engl J Med 350: 221-231, 2004.

4. Duvoix A, Blasius R, Delhalle S, Schnekenburger M, Morceau F, Henry E, Dicato M and Diederich M: Chemopreventive and therapeutic effects of curcumin. Cancer Lett 223: 181-190, 2005.

5. Fojo A, Hamilton TC, Young RC and Ozols RF: Multidrug resistance in ovarian cancer. Cancer 60 (Suppl 8): 2075-2080, 1987.

6. Gillet JP, Efferth T and Remacle J: Chemotherapy-induced resistance by ATP-binding cassette transporter genes. Biochim Biophys Acta 1775: 237-262, 2007. 
7. Shaffer BC, Gillet JP, Patel C, Baer MR, Bates SE and Gottesman MM: Drug resistance: still a daunting challenge to the successful treatment of AML. Drug Resist Updat 15: 62-69, 2012

8. Nabekura T, Yamaki T, Hiroi T, Ueno K and Kitagawa S: Inhibition of anticancer drug efflux transporter P-glycoprotein by rosemary phytochemicals. Pharmacol Res 61: 259-263, 2010.

9. Duncan R: Polymer conjugates as anticancer nanomedicines. Nat Rev Cancer 6: 688-701, 2006.

10. Panyam J, Sahoo SK, Prabha S, Bargar T and Labhasetwar V: Fluorescence and electron microscopy probes for cellular and tissue uptake of poly(D,L-lactide-co-glycolide) nanoparticles. Int J Pharm 262: 1-11, 2003.

11. van Vlerken LE and Amiji MM: Multi-functional polymeric nanoparticles for tumour-targeted drug delivery. Expert Opin Drug Deliv 3: 205-216, 2006.

12. Kumari A, Yadav SK and Yadav SC: Biodegradable polymeric nanoparticles based drug delivery systems. Colloids Surf B Biointerfaces 75: 1-18, 2010.

13. Alexis F, Pridgen E, Molnar LK and Farokhzad OC: Factors affecting the clearance and biodistribution of polymeric nanoparticles. Mol Pharm 5: 505-515, 2008.

14. Baratchi S, Kaur RK, Khoshmanesh K, Vasu P, Ashok C, Hittu M, Paratt A, Krishnakumar S, Sun X, Sahoo SK, et al: Promises of nanotechnology for drug delivery to brain in neurodegenerative diseases. Curr Nanosci 5: 15-25, 2009.

15. Parveen S and Sahoo SK: Nanomedicine: Clinical applications of polyethylene glycol conjugated proteins and drugs. Clin Pharmacokinet 45: 965-988, 2006.
16. Ong AT, Serruys PW, Aoki J, Hoye A, van Mieghem CA, Rodriguez-Granillo GA, Valgimigli M, Sonnenschein K, Regar E, van der Ent M, et al: The unrestricted use of paclitaxelversus sirolimus-eluting stents for coronary artery disease in an unselected population: one-year results of the Taxus-Stent Evaluated at Rotterdam Cardiology Hospital (T-SEARCH) registry. J Am Coll Cardiol 45: 1135-1141, 2005.

17. Daemen J, Wenaweser P, Tsuchida K, Abrecht L, Vaina S, Morger C, Kukreja N, Jüni P, Sianos G, Hellige G, et al: Early and late coronary stent thrombosis of sirolimus-eluting and paclitaxel-eluting stents in routine clinical practice: data from a large two-institutional cohort study. Lancet 369: 667-678, 2007.

18. Stone GW, Midei M, Newman W, Sanz M, Hermiller JB, Williams J, Farhat N, Mahaffey KW, Cutlip DE, Fitzgerald PJ, et al; SPIRIT III Investigators: Comparison of an everolimuseluting stent and a paclitaxel-eluting stent in patients with coronary artery disease: a randomized trial. JAMA 299: 19031913, 2008.§

19. Bierhaus A, Zhang Y, Quehenberger P, Luther T, Haase M, Müller M, Mackman N, Ziegler R and Nawroth PP: The dietary pigment curcumin reduces endothelial tissue factor gene expression by inhibiting binding of AP-1 to the DNA and activation of NF-kappa B. Thromb Haemost 77: 772-782, 1997.

20. Aggarwal S, Ichikawa H, Takada Y, Sandur SK, Shishodia S and Aggarwal BB: Curcumin (diferuloylmethane) down-regulates expression of cell proliferation and antiapoptotic and metastatic gene products through suppression of IkappaBalpha kinase and Akt activation. Mol Pharmacol 69: 195-206, 2006. 